\title{
FRATERNIDADE E SUSTENTABILIDADE: DIÁLOGO NECESSÁRIO PARA FORMAÇÃO DE UMA CONSCIÊNCIA ECOLÓGICA E CONSTRUÇÃO DE UMA SOCIEDADE FRATERNA
}

\author{
Ildete Regina Vale da Silva ${ }^{1}$ \\ Maria Cláudia da Silva Antunes de Souza²
}

\begin{abstract}
Resumo: O objetivo deste artigo "Fraternidade e Sustentabilidade: diálogo necessário para formação de uma consciência ecológica e de construção de uma Sociedade Fraterna" é aproximar e relacionar ideias que permitam (re)pensar o projeto civilizatório, pensando em um projeto cultural comum à Humanidade com fundamento nas Constituições dos Estados nacionais. A justificativa da pesquisa está no fato do Planeta Terra ser o único espaço comum que garante a continuidade da existência da Humanidade, considerando o processo de deterioração que ameaça a própria sobrevivência. A metodologia na investigação foi o método indutivo e na fase de tratamento de dados, o método cartesiano.
\end{abstract}

Palavras-chave: Fraternidade; Sustentabilidade; Sociedade Fraterna; Desenvolvimento Sustentável; Agenda 2030.

\section{FRATERNITY AND SUSTAINABILITY: DIALOGUE NECESSARY FOR THE FORMATION OF AN ECOLOGICAL CONSCIOUSNESS AND CONSTRUCTION OF AN FRATERNAL SOCIETY}

\begin{abstract}
The objective of this article - Fraternity and Sustainability: a dialogue necessary for the formation of an ecological conscience and the construction of a Fraternal Society - is to approximate and relate ideas that allow to (re) think the civilizing project, thinking about a cultural project common to Humanity in the Constitutions of the national States. The justification for this research risedes in the fact that Planet Earth is the only common space that guarantees the continuity of Humanity, considering the deterioration process that threatens its own survival.The methodology in the investigation was the inductive method and in the phase of data processing the cartesian method.
\end{abstract}

Keywords: Fraternity; Sustainability; Fraternal Society. Sustainable Development. 2030 Agenda.

\footnotetext{
${ }^{1}$ Doutora pela Universidade de Perugia UNIPG e UNIVALI. Mestre pela UNIVALI. Professora Colaboradora do Programa de Mestrado em Ciência Jurídica da UNIVALI. http://orcid.org/0000-0003-4671-0457.

${ }^{2}$ Pós-doutora pela Universidade de Passo Fundo - UPF. Doutora pela Universidade de Perugia UNIPG e UNIVALI. Bolsista do PNPD pela Coordenação de Aperfeiçoamento de Pessoal de Nível Superior CAPES. http://orcid.org/0000-0001-5941-1638.

CONPEDI LAW REVIEW | QUITO - EQUADOR | v. 4 | n. 2 | p. 330 - 349 | JUL - DEZ | 2018
} 


\section{INTRODUÇÃO}

Este estudo intitulado Fraternidade e Sustentabilidade: diálogo necessário para formação de uma consciência ecológica e de construção de uma Sociedade Fraterna tem o como tema central propor um diálogo, precipuamente, fundamento na Constituição da República Federativa do Brasil de $1988^{3}$, com intuito de contribuir para (re)pensar o projeto civilizatório, pensando em um projeto cultural comum à Humanidade com fundamento nas Constituições dos Estados nacionais, possibilidade essa que acena, também, para um novo constitucionalismo que emerge na América Latina.

A importância da presente pesquisa justifica-se no fato do Planeta Terra ser o único espaço comum que, até agora, garante a continuidade da existência da Humanidade. O problema da pesquisa decorre do desafio constante que a Humanidade tem na organização convivência humana, considerando o processo de deterioração que ameaça a própria sobrevivência.

O objetivo deste estudo é aproximar e relacionar ideias que permitam (re)pensar o projeto civilizatório, pensando em um projeto cultural comum à Humanidade com fundamento nas Constituições dos Estados nacionais e, para atingir o objetivo proposto, busca-se, inicialmente, tecer considerações sobre a urgente necessidade que se impõe a Humanidade de (re)pensar o projeto civilizatório, propondo-se pensar em um projeto cultural comum com fundamento nas Constituições dos Estados nacionais pelo, fato de ser inegável que o planeta terra é um espaço comum e único a garantir a própria existência. E, nessa perspectiva, instiga-se a refletir sobre o tipo de Sociedade a ser construída.

Apresenta-se a expressão Sociedade Fraterna - cunhada no preâmbulo da CRFB/88 -, verificando-se que essa tem uma base conceitual consistente e com elementos teóricos e práticos para projetar culturalmente uma Sociedade possível para toda Humanidade, identificando a Sustentabilidade como condição de possibilidade para construí-la.

Entende-se que a Sustentabilidade como objetivo da Humanidade representa a única esperança de corrigir a tempo o processo de deterioração do planeta terra. Busca-se compreender e conhecer o sentido da palavra, a fim de demonstrar que, a Sustentabilidade é uma categoria política e jurídica estratégica diretamente relacionada ao Desenvolvimento. Observa-se que, no texto do preâmbulo da CRFB/88, o Desenvolvimento aparece como um

\footnotetext{
${ }^{3}$ Doravante denominada, simplesmente, de Constituição Brasileira de 1988 ou CRFB/88.
} 
dos objetivos do Estado brasileiro e um dos valores supremos da Sociedade Fraterna, identificando que a projeção cultural de um desenvolvimento qualificado como sustentável é a possibilidade de alcançar o meio ambiente ecologicamente equilibrado.

E, na perspectiva de alcançar o meio ambiente ecologicamente equilibrado, identifica-se que, a Agenda 2030 é um plano de ação para alcançar a Sustentabilidade e que contribui significativamente para formação de uma consciência ecológica, porque busca o fortalecimento da paz universal com mais liberdade e a erradicação da pobreza em todas as suas formas e dimensões, traçando objetivos e metas em níveis nacional, regional e global a serem implementados a partir dos Estados nacionais.

Quanto à metodologia adotada, seguem-se os preceitos de Pasold (2018, p.89-100) e utiliza-se, na fase de investigação, o método indutivo, e na fase de tratamento de dados o método cartesiano.

\section{CONSIDERAÇÕES INICIAIS}

A Humanidade não só tem sido constantemente desafiada a (re)pensar o projeto de civilização, como, também, de realizar o seu próprio projeto comum. Faz-se cada vez mais necessário unir esforços e responsabilidades para traçar um caminho que não se resume, apenas, em imaginar a paz, mas de realizá-la, indo além.

Se a Paz foi ideia que alguns países abraçaram ao final da Segunda Guerra Mundial e se, os Direitos Humanos passaram a ser uma legítima preocupação mundial, quando as pesquisas começaram a apontar alterações climáticas e o Dia Mundial do Meio Ambiente foi instituído em 1972 pela Organização das Nações Unidas - ONU -, a Sustentabilidade passou a ser um fundamento tão e quão importante quanto a Paz e a proteção dos Direitos Humanos para (re)pensar o projeto de civilizatório.

Considerando ser inegável o fato de o Planeta Terra ser o único espaço comum que, até agora, garante a continuidade da existência da Humanidade, o desafio consiste em organizar a convivência humana nesse espaço comum, não, apenas, institucionalmente, mas, pela projeção cultural com fundamento nas Constituições de cada Estado nacional.

É preciso, então (re)pensar o projeto civilizatório, pensando em um projeto cultural comum à Humanidade com fundamento nas Constituições dos Estados nacionais, proposta que pode contribuir " [...] a ridurre la presa dele ideologie del benessere e del materialismo, ad 
abbandonare l'economicismo che domina il pensiero e l'agire politico contemporâneo" (HÄBERLE, 2001, p. 186/187). ${ }^{4}$

Na doutrina da Constituição como ciência da cultura proposta por Häberle, o Estado Constitucional é uma aquisição cultural com desafios para o futuro:

La sua tipologia è il risultato e la prestazione di processi culturali, tramandati e sempre nuovamente riappropriati come "patrimonio culturalle", ad esempio nei testi classici. Nel contempo, lo Stato costituzionale è anche uma sfida per il futuro, la pretesa di non regredire dal livello culturale acquisito anzi di conservalo e, semmai, di migliorarlo (per quanto nani seduti spalle di giganti siano in grado di vedere più in là) (HÄBERLE, 2001, p. 32). ${ }^{5}$

Entender o Estado Constitucional como aquisição e progresso cultural é uma contribuição teórica que permite pensar, pelo menos, na órbita da cultura ocidental que, as Constituições democráticas são projetos culturais para pensar e agir politicamente na direção de um projeto comum de organização, não só da convivência humana, mas do sentido que há e que deve ter na própria existência.

A expressão Sociedade Fraterna, cunhada no preâmbulo da CRFB/88 instiga refletir sobre o tipo de Sociedade que se quer construir e, nesse sentido, representa uma importante contribuição do constitucionalismo brasileiro que indica o caminho para (re)pensar o projeto de civilidade pela via de um projeto cultural comum para toda a Humanidade, comprometendo as gerações presentes com o agora e com a continuidade da existência das gerações futuras.

\footnotetext{
${ }^{4}$ [...] para reduzir a adoção da ideologia do bem-estar e do materialismo, para abandonar o economicismo que domina o pensamento e o agir político contemporâneo. (Livre tradução)

${ }^{5} \mathrm{~A}$ sua tipologia é o resultado e a prestação dos processos culturais, que passam de geração para geração e, sempre, são, novamente, retomados como "patrimônio cultural", por exemplo, nos textos dos clássicos. Ao mesmo tempo, o Estado constitucional é também um desafio para o futuro, a pretensão de não regredir no nível cultural adquirido, mas, mantê-lo e, se possível, de melhorá-los (como os anões se sentados nos ombros de gigantes serão capazes de ver mais além). (Livre tradução).
} 


\section{SOCIEDADE FRATERNA: PROJEÇÃO CULTURAL COMUM DE UMA SOCIEDADE POSSÍVEL PARA TODA HUMANIDADE}

A "doutrina da Constituição como ciência cultura" (HÄBERLE, 2001) é um endereço metodológico para entender a $\mathrm{CRFB} / 88$ como projeto cultural e, o preâmbulo da Constituição Federal determina "que o Estado Democrático instituído deve caminhar no sentido de fundar uma Sociedade Fraterna”. (VALE DA SILVA; BRANDÃO, 2015, p.7/8)

A palavra Fraterna que qualifica a Sociedade brasileira torna presente o "princípio esquecido"(BAGGIO,2009) do universalismo político e um importante fundamento da cultura ocidental: a Fraternidade que, juntamente, com a liberdade e a igualdade, constitui uma síntese cultural, "um precedente teórico de notável relevância" e, ainda inédito (BAGGIO, 2009, p.9), porque, o real sentido, ainda não foi extraído:

[...], todavia no se há extraído lo real de las tres palavras de la tricolor; razón por la cual, estas merecen y necesitan tanto más su rescate socialistamente controlado. La lucha por la liberdad crea la igualdad; la igualdad como final explotación y de la dependencia mantiene la liberdad, y la fraternidad es la recompensa de una igualdad en que la nadie necesita, ni puede tampoco, ser un lobo respecto a los demás. (BLOCH, Ernest, 2011, p.302) ${ }^{6}$

A Fraternidade em relação de interdependência com a liberdade e a igualdade constitui "um referencial teórico e prático capaz de recuperar a ideia-força contida na tríade francesa revelada como uma das mais fortes fórmulas de ideais programáticos, inclusive entre aqueles apresentados nas culturas políticas contemporâneas". (VALE DA SILVA; BRANDÃO, 2015, p.125).

O texto do preâmbulo ao qualificar a Sociedade brasileira como Fraterna, resgata a Fraternidade do esquecimento, tornando-a, "na ordem constitucional brasileira, um princípio presente e, por consequência, uma categoria política tão ou mais importante quanto a liberdade e a igualdade" (VALE DA SILVA; BRANDÃO, 2015, p.7/8) e, essa referência constitui um fundamento para melhor compreensão da Constituição Brasileira de 1988 e do tipo de Sociedade que se quer e se deve construir.

\footnotetext{
${ }^{6}$ Contudo, ainda, não foi extraído o real das três palavras da tricolor; razão pela qual, estas merecem e precisam ainda mais de seu resgate socialista controlado. A luta pela liberdade cria igualdade; a igualdade como fim da exploração e da dependência mantêm a liberdade, e a fraternidade é a recompensa de uma igualdade em que ninguém precisa, nem pode tampouco, ser um lobo em relação aos demais. (Livre tradução)
} 
Nesse cenário em que, a globalização produz "a infratextura de uma Sociedademundo" (MORIN, 2013, p.21), a concepção de Sociedade do futuro não poderá ser outra que não a de Sociedade Fraterna:

Encontra-se o caminho para construir uma Sociedade fraterna, dizendo como deverá ser a Sociedade do futuro. Cada vez mais as Sociedades estão diversificadas e interligadas entre si por um ponto crucial, que decorre da crescente desigualdade entre ricos e pobres, quer seja dentro dos Estados nacionais, quer entre os muitos Estados nacionais. E essa é uma realidade que gera problemas de vulnerabilidade individual e coletiva "em" e "entre" vários grupos: mulheres, crianças, idosos, pessoas com deficiência, minorias, indígenas, migrantes, refugiados, pessoas que vivem na pobreza. (VALE DA SILVA; BRANDÃO, 2015, p.143/144)

Sociedade Fraterna "é uma Sociedade com vistas para o futuro", constituída por Pessoas Humanas “estimuladas a perceber o sentido da própria existência e porque percebem o sentido da própria existência, adotam modos de vida que dão sentido à existência do humano e à sua continuidade no tempo e espaço da biosfera". (VALE DA SILVA; BRANDÃO, 2015, p.151-172).

Encontra-se na expressão Sociedade Fraterna a ideia de Sociedade para projetar culturalmente uma Sociedade-mundo com vistas para o futuro, porque tem como bem social a ser protegido "o sentido à existência do humano e à sua continuidade no tempo e espaço da biosfera" (VALE DA SILVA; BRANDÃO, 2015, p.172). Observa-se que

O termo 'biosfera' foi criado por Teilhard de Chardin. É um termo novo, exigido por nossa chegada a um estágio mais avançado no progresso de nosso conhecimento científico e poder material. A biosfera é uma película de terra firme, água e ar que envolve o globo (ou globo virtual) de nosso planeta Terra. É o único habitat atual - e, tanto quanto podemos prever hoje, é também o único habitat jamais viável de todas as espécies de seres vivos que conhecemos, a humanidade inclusive". (TOYNBEE, Arnold. 1987. p. 22.)

Para Canotilho [2015,p.137], quando "se fala proteção constitucional da biosfera e de seus processos essenciais, a primeira categoria que se lembra é o direito ao meio ambiente ecologicamente equilibrado, cartão de visita do constitucionalismo reformado".

O maior bem social a ser protegido em uma Sociedade Fraterna é, sem dúvida o a sentido da existência do humano e a sua continuidade, no tempo e espaço da biosfera. E, essa 
“é uma perspectiva que não se resume, apenas, em imaginar a paz, mas de realizá-la indo além: pela via da" proteção dos Direitos Humanos - "que não se resume equação cidadãonacional - e com vistas à Sustentabilidade como objetivo da humanidade".(VALE DA SILVA, 2015,175).

Verifica-se que a expressão Sociedade Fraterna tem base conceitual consistente para (re)pensar o projeto de civilizatório com elementos para projeção de uma cultura comum a toda Humanidade. A Sociedade Fraterna representa a ideia do tipo de Sociedade possível para agora e com vistas para o futuro, sendo a Sustentabilidade condição de possibilidade para construí-la.

\section{A SUSTENTABILIDADE COMO OBJETIVO DA HUMANIDADE É CONDIÇÃO DE POSSIBILIDADE PARA CONSTRUÇÃO DE UMA SOCIEDADE FRATERNA}

A Sustentabilidade - assim, como, a realização da Paz e a proteção dos Direitos Humanos - é condição de possibilidade para construção de uma Sociedade Fraterna e, neste artigo, lançar-se-á um olhar à Sustentabilidade que representa a única esperança de corrigir em tempo o processo de deterioração do Planeta Terra:

Detectados os problemas ambientais do mundo, desde os anos 1970 até os anos 1990 pleiteávamos mudanças para resgatar um planeta equilibrado para os que viriam depois de nós. Nosso foco eram as gerações futuras - vide o Relatório Brundtland, de 1987.

\section{Hoje a nossa questão é com agora.}

Não dá para deixar para amanhã. (FELMANN, 2011, p.41)

Conhecer e compreender o sentido da palavra Sustentabilidade como categoria política e jurídica estratégica é fundamental para projetar a mudança cultural aliada a formação de uma consciência ecológica para (re)pensar o projeto civilizatório e pensar em um projeto cultural comum à Humanidade, a partir das Constituições dos Estados nacionais e, nessa perspectiva, servindo para melhor interpretar a CRFB/88.

Consultando-se os dicionários, verifica-se que Sustentabilidade é uma palavra que significa "qualidade ou condição do que é sustentável" (MILARÉ,2015,p.830) e sustentável é o “que pode ser sustentado; passível de sustentação”(HOUAISS, 2009,p.1797) Etimologicamente, o radical da palavra Sustentabilidade é sustentar que tem origem no latim 
sustentare que, inobstante, os muito significados possíveis na língua portuguesa, em síntese significa "evitar a queda, manter o equilíbrio" (HOUAISS, 2009,p.1797).

Vale recordar que a história do conceito de Sustentabilidade, segundo Boff (2015, p.31) tem "mais de 400 anos":

O nicho a partir do qual nasceu e se elaborou o conceito de "sustentabilidade" é a silvicultura, o manejo das florestas. Em todo mundo antigo e até o alvorecer da Idade Moderna a madeira era a matéria-prima principal na construção de casas e móveis, em aparelhos agrícolas, como combustível para cozinhar e aquecer as casas. Foi amplamente usada para fundir metais e na construção de barcos, que na época das “descobertas/conquistas” do século XVI singravam todos os oceanos. O uso foi tão intensivo, particularmente na Espanha e em Portugal, as potências marítimas da época, que as florestas começaram a escassear.

Mas foi na Alemanha, em 1560, na Província da Saxônia, que irrompeu, pela primeira vez, a preocupação pelo uso racional das florestas, de forma que elas pudessem se regenerar e se manter permanentemente. Neste contexto surgiu a palavra alemã Nachhaltigkeit, que significa "sustentabilidade". (BOFF, 2015, p.32/33).

Não obstante, o amplo histórico e significado do uso da palavra, dá-se um salto para encontrar na história mais recente, em documento elaborado no ano de 2000, na Assembleia do Milênio promovida pela Organização das Nações Unidas - ONU -, no conjunto de objetivos para o desenvolvimento e erradicação da pobreza no mundo - denominado "As Metas do Milênio da ONU" -, a Sustentabilidade figurando entre os objetivos comuns para toda Humanidade com prazo para alcançá-los até 2015 e,

Em setembro de 2015, líderes mundiais reuniram-se na sede da ONU, em Nova York, e decidiram um plano de ação para erradicar a pobreza, proteger o planeta e garantir que as pessoas alcancem a paz e a prosperidade: a Agenda 2030 para o Desenvolvimento Sustentável, a qual contém o conjunto de 17 Objetivos de Desenvolvimento Sustentável (ODS). (PLATAFORMA, AGENDA 2030).

As breves referências abordadas têm o objetivo de demonstrar que a ideia de Sustentabilidade está diretamente relacionada à ideia de Desenvolvimento qualificado como Sustentável, sendo que esse é um compromisso assumido pelos Estados membros das Nações 
Unidas.

O texto do preâmbulo da Constituição Brasileira de $1988^{7}$ relaciona a palavra Desenvolvimento como um dos objetivos do Estado brasileiro e um dos valores supremos da Sociedade Fraterna:

O objetivo do Estado Democrático instituído está na destinação anunciada no texto do Preâmbulo, ou seja, "assegurar o exercício dos direitos sociais e individuais, a liberdade, a segurança, o bem-estar, o desenvolvimento, a igualdade e a justiça”. Além de garantir o exercício dos direitos sociais e direitos individuais, o texto do Preâmbulo expressa reconhecer, também, que esses direitos não são apenas direitos, mas "valores supremos de uma Sociedade Fraterna, pluralista e sem preconceitos". (VALE DA SILVA; BRANDÃO, 2015, p.127)

Freitas observa que outro tipo de Desenvolvimento que não seja condicionado a Sustentabilidade, é inconstitucional:

Se o desenvolvimento aparece, de modo expresso, no preâmbulo da Constituição, a sustentabilidade surge, por assim dizer, como qualificação constitucional insuprimivel do desenvolvimento, sob influxo do art. 225. Ou seja, consoante a Carta modo expresso que, o desenvolvimento que importa é aquele que se constitui mutuamente com a sustentabilidade, condicionada por ela. Qualquer outro será inconstitucional. (FREITAS, 2.016, p.51).

A Sustentabilidade é, então, "a qualificadora do desenvolvimento que se almeja para nação brasileira" (OLIVEIRA; LANGOSKI, 2016, p.43) e, considerando o exposto, a referência expressa da palavra Desenvolvimento no preâmbulo da Constituição Brasileira de 1988, como objetivo do Estado Democrático instituído e como valor supremo de uma Sociedade Fraterna, não permite outra ideia que não seja a de Desenvolvimento Sustentável.

O conceito de Desenvolvimento Sustentável entrou no discurso público pelo documento Nosso Futuro Comum, publicado em 1987: “Desenvolvimento Sustentável é

7 Texto do Preâmbulo da Constituição da República Federativa do Brasil de 1988 -'Nós, representantes do povo brasileiro, reunidos em Assembleia Nacional Constituinte para instituir um Estado Democrático, destinado a assegurar o exercício dos direitos sociais e individuais, a liberdade, a segurança, o bem-estar, o desenvolvimento, a igualdade e a justiça como valores supremos de uma sociedade Fraterna, pluralista e sem preconceitos, fundada na harmonia social e comprometida, na ordem interna e internacional, com a solução pacífica das controvérsias, promulgamos, sob a proteção de Deus, a seguinte CONSTITUIÇÃO DA REPÚBLICA FEDERATIVA DO BRASIL." (BRASIL,CRFB, 1988)

CONPEDI LAW REVIEW | QUITO - EQUADOR | v. 4 | n. 2 | p. 330 - 349 | JUL - DEZ | 2018 
aquele que atende às necessidades do presente sem comprometer a possibilidade de as gerações futuras atenderem a suas próprias necessidades" (ONUBr).

A ideia de Desenvolvimento Sustentável decorre da compatibilização entre meio ambiente e o desenvolvimento, significando

[...] considerar os problemas ambientais dentro de um processo contínuo de planejamento, atendendo-se adequadamente às exigências de ambos e observando-se as suas inter-relações particulares em cada contexto sociocultural, político, econômico e ecológico, dentro de uma dimensão de tempo/espaço. (SOUZA; MAFRA, 2017, p. 319)

Para Ferrer, Glasenapp e Cruz (2014,p.145), “o Desenvolvimento Sustentável como uma via para se alcançar a Sustentabilidade", podendo "ser mais um dos caminhos para alcançar uma sociedade sustentável". O que importa para Freitas (2016, p.34) "é a Sustentabilidade nortear o desenvolvimento e, não o contrário".

A projeção cultural de desenvolvimento qualificado como sustentável é a possibilidade de alcançar o meio ambiente ecologicamente equilibrado, representando, assim, a única esperança de corrigir em tempo processo de deteriorização do planeta terra frente o perigo real que ameaça a continuidade da existência da Humanidade:

Mais que tudo, trata-se de migrar do século XX para o século XXI. Uma mudança que deverá acontecer ser operada dentro de um território ainda pouco explorado: a nossa mente. É preciso ter consciência de que essa é uma mudança cultural. Rumamos a um novo pensamento, uma nova maneira de enxergar o mundo. Uma mudança de valores. Radical. (FELMANN, 2011, p.42).

A Sustentabilidade como condição de possibilidade para construir uma Sociedade Fraterna e, como objetivo da Humanidade é uma categoria política e jurídica estratégica que, diretamente relacionada a ideia de Desenvolvimento permite ao Estado brasileiro (re)pensar o projeto civilizatório e projetar uma cultura comum à Humanidade, através da CRFB/88 pelo compromisso que há em alcançar o meio ambiente ecologicamente equilibrado, compromisso esse que coaduna com aquele assumido pelos Estados membros das Nações Unidas. 
4 MEIO AMBIENTE ECOLOGICAMENTE EQUILIBRADO NA CONSTITUIÇÃO DA REPÚBLICA FEDERATIVA DO BRASIL DE 1988

A CRFB/88 tem como núcleo principal da proteção do meio ambiente no artigo $225^{8}$. Não obstante a complexidade teórica e prática da normatividade constitucional, toma-se o enunciado no caput do artigo 225 da CRFB/88 para destacar alguns aspectos que auxiliam a compreender o sentido da Sustentabilidade como qualificadora do Desenvolvimento relacionado no preâmbulo da Constituição Brasileira de 1988.

O caput do artigo 225 da Constituição Brasileira de 1988 dispõe que:

Todos têm direito ao meio ambiente ecologicamente equilibrado, bem de uso comum do povo e essencial à sadia qualidade de vida, impondo-se ao Poder Público e à coletividade o dever de defendê-lo e preservá-lo para as presentes e futuras gerações. (BRASIL, CRFB, 1988)

Canotilho e Leite (2015,p. 133) observam que a imprevisibilidade dos sistemas naturais requer que a expressão equilibro ecológico seja utilizado de forma dinâmica e não estática, a fim de "assegurar que tal estado dinâmico, em que se processa os fenômenos naturais, seja conservado, deixando que a natureza siga seu próprio curso".

\footnotetext{
${ }^{8}$ Art. 225 da CRFB/88. "Todos têm direito ao meio ambiente ecologicamente equilibrado, bem de uso comum do povo e essencial à sadia qualidade de vida, impondo-se ao Poder Público e à coletividade o dever de defendêlo e preservá-lo para as presentes e futuras gerações. $§ 1^{\circ}$ Para assegurar a efetividade desse direito, incumbe ao Poder Público: I - preservar e restaurar os processos ecológicos essenciais e prover o manejo ecológico das espécies e ecossistemas; II - preservar a diversidade e a integridade do patrimônio genético do País e fiscalizar as entidades dedicadas à pesquisa e manipulação de material genético; III - definir, em todas as unidades da Federação, espaços territoriais e seus componentes a serem especialmente protegidos, sendo a alteração e a supressão permitidas somente através de lei, vedada qualquer utilização que comprometa a integridade dos atributos que justifiquem sua proteção; IV - exigir, na forma da lei, para instalação de obra ou atividade potencialmente causadora de significativa degradação do meio ambiente, estudo prévio de impacto ambiental, a que se dará publicidade; V - controlar a produção, a comercialização e o emprego de técnicas, métodos e substâncias que comportem risco para a vida, a qualidade de vida e o meio ambiente; VI - promover a educação ambiental em todos os níveis de ensino e a conscientização pública para a preservação do meio ambiente; VII proteger a fauna e a flora, vedadas, na forma da lei, as práticas que coloquem em risco sua função ecológica, provoquem a extinção de espécies ou submetam os animais a crueldade. $\S 2^{\circ}$ Aquele que explorar recursos minerais fica obrigado a recuperar o meio ambiente degradado, de acordo com solução técnica exigida pelo órgão público competente, na forma da lei. $\S 3^{\circ}$ As condutas e atividades consideradas lesivas ao meio ambiente sujeitarão os infratores, pessoas físicas ou jurídicas, a sanções penais e administrativas, independentemente da obrigação de reparar os danos causados. $\S 4^{\circ}$ A Floresta Amazônica brasileira, a Mata Atlântica, a Serra do Mar, o Pantanal Mato-Grossense e a Zona Costeira são patrimônio nacional, e sua utilização far-se-á, na forma da lei, dentro de condições que assegurem a preservação do meio ambiente, inclusive quanto ao uso dos recursos naturais. $\S 5^{\circ}$ São indisponíveis as terras devolutas ou arrecadadas pelos Estados, por ações discriminatórias, necessárias à proteção dos ecossistemas naturais. $\S 6^{\circ}$ As usinas que operem com reator nuclear deverão ter sua localização definida em lei federal, sem o que não poderão ser instaladas. $7^{\circ}$ Para fins do disposto na parte final do inciso VII do $\S 1^{\circ}$ deste artigo, não se consideram cruéis as práticas desportivas que utilizem animais, desde que sejam manifestações culturais, conforme o $\S 1^{\circ}$ do art. 215 desta Constituição Federal, registradas como bem de natureza imaterial integrante do patrimônio cultural brasileiro, devendo ser regulamentadas por lei específica que assegure o bem-estar dos animais envolvidos". (BRASIL, CRFB, 1988)
}

CONPEDI LAW REVIEW | QUITO - EQUADOR | v. 4 | n. 2 | p. 330 - 349 | JUL - DEZ | 2018 
O meio ambiente ecologicamente equilibrado presente na redação do artigo 225 da CRFB/88, "precisa ser muito demarcado, sob pena de se perturbar a aplicação dos dispositivos constitucionais e das normas infraconstitucionais dela dependentes", sendo que a noção de equilíbrio está baseada "na ideia de que todos os organizamos vivos estão de algum modo inter-relacionado no meio ambiente natural”. (CANOTILHO; LEITE,2015, p.133).

Observa-se que, na perspectiva de construir uma Sociedade Fraterna, a referência ao vocábulo todos, na frase "Todos têm direito ao meio ambiente ecologicamente equilibrado" não permite interpretação restritiva da tutela prevista quanto ao titular o beneficiário do direito - e, também, dos deveres -, assim como Canotilho e Leite (2015, p.131), entende-se que "o melhor entendimento é aquele que garante a qualquer pessoa, residente ou não" no País, "o benefício de tal direito".

Verifica-se que a imposição do dever de defender e preservar o meio ambiente ecologicamente equilibrado para as gerações presentes e futuras, tanto ao Poder Público quanto à coletividade, revela a superação da dicotomia entre público e privado, que é, importante característica do novo constitucionalismo humanista:

[...] o reconhecimento de que nenhum indivíduo vive fora da sociedade e de que, em consequiência, tudo o que afeta os direitos de outros indivíduos têm significação social, rompeu-se a estrita separação entre áreas públicas e privadas.

[...]. o novo constitucionalismo é humanista, no sentido de tratar a pessoa humana como o primeiro dos valores e de condicionar todas as ações do indivíduo com repercussão social ao respeito desse valor". (DALLARI, 2013, p,146)

O enunciado do caput artigo 225 da CRFB/88 tem elementos que convergem com o sentido da palavra Sustentabilidade como categoria política e jurídica que qualifica o tipo de Desenvolvimento que, no preâmbulo da Constituição Brasileira de 1988 é objetivo do Estado democrático instituído e valor supremo de uma Sociedade Fraterna.

Contudo, sabe-se que, no Estado brasileiro, a promoção do Desenvolvimento Sustentável não está limitada ao que está previsto no artigo 225 da CRFB/88 e, a formação de uma consciência ecológica para defesa e preservação do meio ambiente incluiu compromissos não só com a ordem interna, mas, também, com a ordem internacional, tal como dispõe o texto do preâmbulo da CRFB/88: “[...] valores supremos de uma sociedade Fraterna, 
pluralista e sem preconceitos, fundada na harmonia social e comprometida, na ordem interna e internacional, com a solução pacífica das controvérsias, [...]”. (BRASIL, CRFB, 1988).

E, na perspectiva de alcançar o meio ambiente ecologicamente equilibrado pela via do Desenvolvimento Sustentável, o conjunto dos dezessete Objetivos de Desenvolvimento Sustentável (ODS) da Agenda 2030 é o plano de ação necessário para pensar e agir politicamente à formação de uma consciência ecológica.

\section{5- AGENDA 2030: PLANO DE AÇÃO NECESSÁRIO PARA FORMAÇÃO DE UMA CONSCIÊNCIA ECOLÓGICA}

A reunião de chefes de Estado e de Governo e altos representantes na sede das Nações Unidas em Nova York, de 25 a 27 de setembro de 2015, decidiram sobre os novos Objetivos de Desenvolvimento Sustentável globais e, declararam que em nome dos povos que servem, adotaram

[...] uma decisão histórica sobre um conjunto de Objetivos e metas universais e transformadoras que é abrangente, de longo alcance e centrado nas pessoas. Comprometemo-nos a trabalhar incansavelmente para a plena implementação desta Agenda em 2030. Reconhecemos que a erradicação da pobreza em todas as suas formas e dimensões, incluindo a pobreza extrema, é o maior desafio global e um requisito indispensável para o desenvolvimento sustentável. Estamos empenhados em alcançar o desenvolvimento sustentável nas suas três dimensões - econômica, social e ambiental - de forma equilibrada e integrada. Também vamos dar continuidade às conquistas dos Objetivos de Desenvolvimento do Milênio e buscar atingir suas metas inacabadas. (ONUBr, 2015, acesso 24 mai 2018.)

Na frase inicial do preâmbulo da Agenda 2030, verifica-se a afirmação que esta é um plano de ação para as pessoas, para o planeta e para prosperidade e, na sequência, ao mesmo tempo que faz um convite aos países e a todas as partes interessadas a atuarem de forma colaborativa, assume o compromisso de, nessa jornada, não deixar ninguém para trás:

Preâmbulo

Esta Agenda é um plano de ação para as pessoas, para o planeta e para a prosperidade. Ela também busca fortalecer a paz universal com mais liberdade. Reconhecemos que a erradicação da pobreza em todas as suas 
formas e dimensões, incluindo a pobreza extrema, é o maior desafio global e um requisito indispensável para o desenvolvimento sustentável.

Todos os países e todas as partes interessadas, atuando em parceria colaborativa, implementarão este plano. Estamos decididos a libertar a raça humana da tirania da pobreza e da penúria e a curar e proteger o nosso planeta. Estamos determinados a tomar as medidas ousadas $\mathrm{e}$ transformadoras que são urgentemente necessárias para direcionar o mundo para um caminho sustentável e resiliente. Ao embarcarmos nesta jornada coletiva, comprometemo-nos que ninguém seja deixado para trás.

Os 17 Objetivos de Desenvolvimento Sustentável e 169 metas que estamos anunciando hoje demonstram a escala e a ambição desta nova Agenda universal. Eles se constroem sobre o legado dos Objetivos de Desenvolvimento do Milênio e concluirão o que estes não conseguiram alcançar. Eles buscam concretizar os direitos humanos de todos e alcançar a igualdade de gênero e o empoderamento das mulheres e meninas. Eles são integrados e indivisíveis, e equilibram as três dimensões do desenvolvimento sustentável: a econômica, a social e a ambiental.(ONUBr, 2015).

A Agenda 2030 é o plano de ação necessário à formação de uma consciência ecológica, porque que busca do fortalecimento da paz universal com mais liberdade e a erradicação da pobreza em todas as suas formas e dimensões, considerando a pobreza extrema como requisito indispensável para o Desenvolvimento Sustentável e declarando o firme compromisso de utilizar no máximo os 17 objetivos do Desenvolvimento Sustentável e as 169 metas “para transformar o nosso mundo para melhor em 2030”.(ONUBr, 2015).

Os objetivos do Desenvolvimento Sustentável e metas estabelecem uma visão de mundo de extremamente ambiciosa e transformadora, sendo a "nova agenda guiada pelos propósitos e princípios da Carta das Nações Unidas, incluindo o pleno respeito pelo direito internacional", sem deixar de reconhecer "que cada país é o principal responsável pelo seu próprio desenvolvimento econômico e social". (ONUBr, 2015).

A parceria global revitalizada é uma exigência para garantir a execução da nova agenda e

Esta parceria irá trabalhar em um espírito de solidariedade global, em especial a solidariedade com os mais pobres e com as pessoas em situações vulneráveis. Ele facilitará um engajamento global intensivo em apoio à 
implementação de todos os Objetivos e metas, reunindo governos, setor privado, sociedade civil, o Sistema das Nações Unidas e outros atores e mobilizando todos os recursos disponíveis. (ONUBr, 2015).

A nova agenda estabelece e apoia estratégias e programas de ação relevantes que buscam meios de implementar os "17 Objetivos de Desenvolvimento Sustentável com 169 metas associadas que são integradas e indivisíveis", em níveis nacional, regional, global que facilitam a formação de uma consciência ecológica, a partir dos Estados nacionais.

A formação de uma consciência ecológica, a partir dos Estados nacionais, é o caminho para transformação deste mundo, porque são poucos os que, realmente, tem consciência que projeto civilizatório tem adotado, predominantemente, um estilo de vida “devorante, compulsivo e pouco amigável” (FREITAS, 2016, p.25), o qual representa um perigo real que pode inviabilizar a permanência da existência da Humanidade.

A percepção dos riscos comuns e a defesa desses é fator determinante na organização da convivência entre as Pessoas Humanas e, destas com todas as espécies de seres vivos que habitam na Biosfera, a fim de garantir a existência no presente, viabilizando-a no futuro.

Logo, a reflexão sobre o tipo de Sociedade a ser construída demanda compromissos prévios como os estabelecidos na Agenda 2030 e, essa tem um plano de ação para alcançar a Sustentabilidade como objetivo da Humanidade pela via do Desenvolvimento Sustentável,

A Sustentabilidade como objetivo da Humanidade pela via do Desenvolvimento Sustentável é um guia de ação para Humanidade que, além de assegurar um ambiente ecologicamente equilibrado, assegura, por esta via, a necessária redefinição dos valores de orientação e objetivos educacionais sobre o tipo de Sociedade a ser construída.

Logo, a formação de uma consciência ecológica é imprescindível para (re)pensar o projeto civilizatório e projetar uma cultura comum à Humanidade, de organização, não só da convivência humana, mas do sentido que há e que deve ter na própria existência e da sua continuidade no tempo e espaço a Biosfera.

A expressão Sociedade Fraterna, cunhada no preâmbulo da Constituição Brasileira de 1988 que, tem a Sustentabilidade - assim, como a Paz e a proteção dos Direitos Humanos como condição de possibilidade, instiga refletir sobre o tipo de Sociedade que se quer construir.

Desta forma, verifica-se que a transformação do nosso mundo passa pelo diálogo 
entre a Fraternidade e a Sustentabilidade que, aqui trabalho, se fez à luz da CRFB/88, representando uma importante contribuição do constitucionalismo brasileiro para (re)pensar o projeto de civilidade pela via da projeção cultural comum de Sociedade para toda a Humanidade.

\section{CONSIDERAÇÕES FINAIS}

A proposta de diálogo entre a Fraternidade e a Sustentabilidade, embora, precipuamente fundamentada na Constituição Brasileira de 1988 e, ainda que possa parecer pretensiosa, representa uma importante contribuição do constitucionalismo brasileiro para (re)pensar o projeto de civilidade pela via da projeção cultural comum à Humanidade com fundamento nas Constituições dos Estados nacionais, possibilidade essa que acena, também, para um novo constitucionalismo que emerge na América Latina

Buscou-se demonstrar que, contemporaneamente, tanto a Fraternidade como a Sustentabilidade são categorias imprescindíveis para o pensamento político e jurídico constitucional brasileiro em razão da base conceitual que permite coadunar conhecimentos e ideias essenciais para interpretação da Constituição Brasileira de 1988,

Para iniciar o diálogo e oferecer respostas ao problema proposto, instigou-se a reflexão sobre o tipo de Sociedade a ser construída frente ao desafio que a Humanidade tem em organizar a convivência humana, considerando o processo de deterioração que ameaça a própria sobrevivência, apresentou-se a Fraternidade - princípio do universalismo político, tal como a Liberdade e a Igualdade - e, como qualificadora do tipo de Sociedade expressa no preâmbulo da CRFB/88. E, a expressão Sociedade Fraterna tem elementos conceituais que permite projetar culturalmente, no presente e com vistas para o futuro, tanto a Sociedade brasileira como, também, a Sociedade-mundo, porque o bem social maior a ser protegido é "o sentido à existência do humano e à sua continuidade no tempo e espaço da biosfera". (VALE DA SILVA, BRANDÃO, p.151-172)

Se o bem social maior a ser protegida é o sentido à existência do humano e à sua continuidade no tempo e espaço da biosfera, contemporaneamente, a Sustentabilidade como objetivo da Humanidade é uma categoria essencial para pensar o tipo de Sociedade a ser construída e, tal como a Paz e a proteção dos Direitos Humanos é condição de possibilidade para construção de uma Sociedade Fraterna. 
Identificou-se que há, no compromisso firmado pelos Estados membros das Nações Unidas uma relação direta entre a Sustentabilidade e o Desenvolvimento, sendo este, identificado no texto do preâmbulo da CRFB/88 como um dos objetivos e um dos valores supremos de uma Sociedade Fraterna, referência essa que, permite considerar que, no Brasil, não é mais possível aceitar outro tipo de Desenvolvimento que não seja o Desenvolvimento Sustentável.

Identificou-se que a projeção cultural de um desenvolvimento qualificado como sustentável é a possibilidade de alcançar o meio ambiente ecologicamente equilibrado que, conforme disposto no artigo 225 da CRFB/88 é direito de todos. E, para melhor defender e preservar o meio ambiente ecologicamente equilibrado, a ideia de direito deve, necessariamente, corresponder, também, a ideia de dever e, a palavra todos deve significar qualquer Pessoa Humana, independentemente, de ser ou não residente no País.

Para melhor defender e preservar o meio ambiente, conclui-se que a formação de uma consciência ecológica é fundamental e a Agenda 2030 é um plano de ação que abre caminho para projetar culturalmente a transformação deste mundo, a partir dos Estados nacionais. E, especificamente, no Brasil, a Agenda 2030 representa um plano de ação significativo para orientar e educar o saber e as ações práticas, consoante os objetivos e valores constitucionais que buscam alcançar o meio ambiente ecologicamente equilibrado e promover o Desenvolvimento Sustentável.

A formação de uma consciência ecológica é imprescindível para alcançar o meio ambiente ecologicamente equilibrado e promover o Desenvolvimento Sustentável, sendo este, a via de principal acesso a Sustentabilidade como objetivo da Humanidade. E, a Sustentabilidade como objetivo da Humanidade tem elementos teóricos e práticos para garantir a continuidade da existência da Humanidade frente ao processo de deterioração do planeta terra que ameaça a sua própria sobrevivência e desafia a (re)pensar o projeto civilizatório.

Para (re)pensar o projeto civilizatório frente a constante ameaça a própria sobrevivência da Humanidade, é preciso organizar a convivência no Planeta Terra, projetando culturalmente uma Sociedade possível para todos, encontrando-se na expressão Sociedade Fraterna, cunhada no preâmbulo da Constituição Brasileira de 1988, o tipo de Sociedade com base conceitual consistente para estimular as Pessoas Humanas a perceberem que, além do sentido que deve haver na existência do humano no Planeta Terra, a sobrevivência e a 
continuidade da mesma, no tempo e espaço da biosfera, está constantemente ameaçada.

E, pelo exposto, em resposta ao problema da pesquisa, ou seja, diante do constante desafio que a Humanidade tem em organizar a convivência humana, considerando o processo de deterioração que ameaça a própria sobrevivência, conclui-se que a Fraternidade e Sustentabilidade são categorias políticas e jurídicas estratégicas que servem para melhor interpretar a Constituição Brasileira de 1988. E, a expressão Sociedade Fraterna possibilita estabelecer o diálogo necessário para enfrentar a urgente necessidade que se impõe de (re)pensar o projeto civilizatório e pensar um projeto cultural comum à Humanidade com fundamento nas Constituições dos Estados nacionais, sendo essa uma possibilidade que acena, também, para um novo constitucionalismo que emerge na América Latina, uma vez que é inegável o fato que o Planeta Terra é um espaço comum e único a garantir a própria existência.

\section{REFERENCIAS}

BAGGIO, Antonio Maria.(Org). O Princípio Esquecido/2: Exigências, recursos e definições da Fraternidade na política. Trad. Durval Cordas, Luciano Menezes Reis. Vargem Grande Paulista: Cidade Nova, 2009.

BLOCH, Ernest. Derecho Natural y Dignidad Humana. Edición, estúdio preliminar y notas de Francisco Serra. Traducción del alemán de Felipe González Vicén. Madrid: Dykinson, 2011.

BOFF, Leonardo. Sustentabilidade. O que é - O que não é. $4^{\mathrm{a}}$. ed. Petrópolis/RJ: Vozes, 2015.

BRASIL. Constituição da República Federativa do Brasil de 1988. Diário Oficial da República Federativa do Brasil. Disponível em: < BRASIL. Constituição da República Federativa do Brasil de 1988. Diário Oficial da República Federativa do Brasil. Disponível em: <http://www.planalto.gov.br/ccivil_03/Constituicao/Constituicao.htm>. Acesso em: 10 mai. 2018.

CANOTILHO, José Joaquim Gomes; LEITE, José Rubes Morato (Orgs.). Direito Constitucional Ambiental Brasileiro. 6 a .ed.rev. -São Paulo:Saraiva, 2015. 
DALLARI, Dalmo de Abreu. Constituição na vida dos povos: da Idade Média ao Século XXI. 2a. ed. São Paulo:Saraiva, 2013.

DICIONÁRIO DO AURÉLIO. https://dicionariodoaurelio.com/sustentabilidade. Acesso em 03 maio 2018.

FELDMANN, Fabio. Sustentabilidade planetária, onde entro nisso? São Paulo: Terra Virgem, 2011.

FERRER, Gabriel Real; GLASENAPP, Maikon Cristiano; CRUZ, Paulo Márcio. Sustentabilidade: um novo paradigma para o direito. Revista Novos Estudos Jurídicos Eletrônica, Vol. 19 - n. 4 - Edição Especial 2014. p. 145.

FREITAS, Juarez. Sustentabilidade: direito ao futuro. $3^{\text {a }}$.ed. Belo Horizonte: Forum, 2016.

HÄBERLE, Peter. Per una Dottrina della Costituzione come Scienza della Cultura. Roma: Carocci editore. 2001.

HOUAISS, Antônio; VILLAR, Mauro de Salles. Dicionário Houaiss da língua portuguesa. Rio de Janeiro: Objetiva, 2009.

MILARÉ, Édis. Dicionário de Direito Ambiental. 1ª.ed. São Paulo: Revista dos Tribunais, 2015.

MORIN, Edgar. A VIA para o futuro da humanidade. Tradução de Edgard de Assis Carvalho, Mariza Perassi Bosco. Rio de Janeiro:Bertrand Brasil, 2013.

OLIVEIRA, Olga Maria Boschi Aguiar de; LANGOSKI, Deisemara Turatti. A sustentabilidade como expressão do princípio da Fraternidade. In. VERONESE, Josiane Rose Petry; OLIVEIRA, Olga Maria Boschi Aguiar de; MOTA, Sergio Ricardo Ferreira. (Orgs.) Florianópolis:Insular, 2016.

ONUBR. Nações Unidas no Brasil. Disponível em https://nacoesunidas.org/acao/meioambiente/. Acesso em 10 de maio de 2018.

ONUBR. Nações Unidas no Brasil. OBJETIVOS DE DESENVOLVIMENTO SUSTENTÁVEL: Transformando Nosso Mundo: A Agenda 2030 para o Desenvolvimento 
Sustentável. https://nacoesunidas.org/wp-content/uploads/2015/10/agenda2030-pt-br.pdf. Acesso em 24 de maio de 2018.

PASOLD, Cesar Luiz. Metodologia da Pesquisa Jurídica: teoria e prática. 14. ed.rev.atual.e ampl.Florianópolis: Empório Modara, 2018.

PLATAFORMA, AGENDA 2030, http://www.agenda2030.org.br/. Acesso 03 maio 2015)

SOUZA, Maria Claudia da Silva Antunes; MAFRA, Juliete Ruana. SUSTENTABILIDADE

\section{E SEUS REFLEXOS DIMENSIONAIS NA AVALIAÇÃO AMBIENTAL}

ESTRATÉGICA: o ciclo do equilíbrio do bem estar. In: GARCIA, Denise Schmitt Siqueira; DANTAS, Marcelo Buzaglo; GIMENEZ, Andrés Molina (Organizadores). SOUZA, Maria Claudia da Silva Antunes; VIEIRA, Ricardo Stanziola; FERRER, Gabriel Real. Coleção Estado, Transnacionalidade e Sustentabilidade. TOMO 3. Sociedade, Governança e Meio Ambiente. Itajaí: UNIVALI, 2017.

TOYNBEE, Arnold. A Humanidade e a Mãe-Terra. Rio de Janeiro: Guanabara, 1987.

VALE DA SILVA, Ildete Regina. A Fraternidade como um valor que o Direito pode e deve (re)construir: Uma abordagem à luz dos Direitos Humanos e dos Direitos Fundamentais. Disponível em: https://www6.univali.br/tede/tde_busca/arquivo.php?codArquivo=722.

VALE DA SILVA, Ildete Regina; BRANDÃO, Paulo de Tarso. CONSTITUIÇÃO E FRATERNIDADE. O Valor Normativo do Preâmbulo da Constituição. Curitiba: Juruá, 2015 . 